\title{
Meiotic Behavior of Induced Reciprocal Translocation Heterozygote during Microsporogenesis of Brassica campestris L. (Brassicaceae)
}

\author{
Girjesh Kumar, and Kshama Dwivedi* \\ Plant Genetics Laboratory, Department of Botany, University of Allahabad, \\ Allahabad-211002, U.P., India
}

Received August 1, 2012; accepted February 23, 2013

\begin{abstract}
Summary Although the occurrence of reciprocal translocation has already been discovered in plants, this is the first report on the striking phenomenon of reciprocal translocation (RT) induced through combined treatment in Brassica campestris L. accession number-IC363713. The seeds were subjected to four doses of gamma rays i.e. $15,30,45,60 \mathrm{Kr}$, followed by $0.3 \%$ EMS solution, and were sown in triplicates. Occurrence of RT was identified by the reduced reproductive success of plants, which was authenticated by cytological analysis that revealed the high incidence of multivalent association, forming either a ring or a chain. Rings were discerned to occur in alternate orientation, forming eight-shaped structure while simple loops were noticed erratically when the chromosomes were oriented adjacently. On the other hand, the lack of chiasmata in chromosomes was the cause of chains as multivalent association. No such phenomenon has been observed in non-treated sets. Moreover, the spectrum of multivalent association (MA) and univalents in the pollen mother cells (PMCs) from diakinesis to metaphase-I has been found to be increased in parallel with the dose of treatment, although the frequency of bivalents showed a gradual decline in their percentages. The frequency of quadrivalents has prevailed both in ring and chain forms, other than trivalent, hexavalent and other associations. Meanwhile, pollen fertility drastically decreased with the increasing trend of multivalent association. Notwithstanding RT, various other structural chromosome abnormalities, such as unequal separation, laggards and bridges during meiotic course, were recorded.
\end{abstract}

Key words Brassica campestris L., Combined treatment, Multivalent association, Pollen fertility, Reciprocal translocation.

Translocation heterozygotes, having the potential for creating and conserving specific gene combinations, are generally identified by reduced reproductive capacity and the presence of multivalents during reduction division (Sharma and Gohil 2011). Plants bearing translocations are known as heterozygotes as only one of the chromosomes, of a non-homologous pair, is involved (Kumar and Singh 2003). During meiosis, the random mating of two non-homologous chromosomes followed by the exchange of chromosomal segments that involve the breakage and rejoining of the arms of two non-homologous chromosomes results in the formation of RT heterozygotes or double interchange complexes. Chromosomal breakage is a common feature both in plants and animals (Mahama et al. 1998) and these broken segments, if unable to join or restitute, might result in inversions, a kind of chromosomal aberration that leads to the formation of bridges during anaphase. The occurrence of RT in animals as consequence of uncharacteristic male meiosis is quite destructive, and may be responsible for mental retardation. On the other hand, reciprocal translocation (RT) in plants may lead to the formation of semi-sterile plants; it may be the cause of male ste-

* Corresponding author e-mail: kshama.dwivedi@gmail.com

DOI: $10.1508 /$ cytologia. 78.43 
rility, female sterility or, in rarer cases, both types of sterility could prevail. A positive aspect of RT is that the sterile male plants allows hybrid seed production and sterility in female plants allows the production of seedless varieties (Zhang et al. 2012); hence, this approach could be utilized in horticulture.

Although the spontaneous incidence of RT in nature is quite rare, the first report on naturally occurring RT was by Belling (1914) in the Florida velvet bean (Stizolobium deeringianum); later, Gupta et al. (2010) reported on naturally occurring RT in Artemisia parviflora (Asteraceae) from Parvati Valley in Kullu. Muller (1930) was first to report on X-ray-induced translocations in Drosophila and since then there has been a collection of mutagen induced reciprocal translocations (RT) reported in both plants and animals by many researchers (Hsieh 1961, Generoso et al. 1974, Verma and Raina 1982, Sareen et al. 1998, Kumar and Singh 2003, Shukla Nee Tripathi and Kumar 2009, Zhang et al. 2012).

Hence, the present investigation is concerned with the incidence and behavior of RT heterozygotes in the oilseed rape Brassica campeatris L., as induced through combined treatment of gamma rays and EMS. The aim of the present communication is to become acquainted with the cytological possibilities and particularities of RT during male meiosis and to depict its impact on the fertility of present crop.

\section{Materials and methods}

The material for present study was procured from National Bureau of Plant Genetics Resources (NBPGR), New Delhi. Pure and healthy seeds were stored at almost 10\% moisture content because seeds stored at 10\% moisture content maintain high viability (Kalyani et al. 1995). Seeds were treated with a combined treatment and cytological observations were made as follows:

Seed treatment: seeds were subjected to four doses of ionizing radiation i.e. $15,30,45,60 \mathrm{Kr}$ by the gamma-chamber type ${ }^{60} \mathrm{Co}$ at the dose rate of $20 \mathrm{~s} / \mathrm{K} \mathrm{rad}$ and immediately they were treated with $0.3 \%$ of EMS $\left(\mathrm{CH}_{3} \mathrm{SO}_{3} \mathrm{C}_{2} \mathrm{H}_{5}\right)$ solution ( $\left.\mathrm{v} / \mathrm{v}\right)$ for $5 \mathrm{~h}$ with intermitted stirring.

Microsporogenesis studies: young floral buds of suitable sizes were fixed in vials containing glacial acetic acid and ethyl alcohol $(1: 3, \mathrm{v} / \mathrm{v})$ for $24 \mathrm{~h}$ and refrigerated in $70 \%$ alcohol at $4{ }^{\circ} \mathrm{C}$ until use. Slides were prepared using the anther squash technique with $2 \%$ standard acetocarmine stain with traces of ferric chloride (Evans and Reed 1981). Slides were carefully examined under an optical microscope (Olympus CH20i). Three plants were randomly selected for each dose for cytological analysis, chromosome counts were made and abnormalities recorded. It may be noted this was very difficult because chromosomes were extremely small and did not easily separate during meiotic preparation. Pollen fertility was estimated using a glycerol-acetocarmine $(1: 1)$ mixture. Pollen grains with stained nuclei were considered fertile while withered and unstained pollen grains without nuclei were counted sterile. A Pinnacle pctv capture device was used for taking photomicrographs of chromosome. Statistica-8 software by Stat soft was used for statistical analysis.

\section{Results}

Brassica campestris L. exhibits 10 bivalents at metaphase-I and 10:10 separation at anaphaseI during the normal course of reduction division. The aforementioned configuration of chromosomes drastically fluctuated in the pollen mother cells (PMCs) of treated sets, exhibiting a high incidence of multivalent association as a ring or a chain. In some cases, other associations, namely trivalent, octavalent, decavalent and dodecavalent, were also noticed. In the present study, the association of chromosomes in 4 or 6 reflects the involvement of 2 or 3 non-homologous chromosomes, respectively. PMCs having double interchange often occurred at diakinesis-metaphase I, displaying alternate, adjacent and, in some cases, random types of orientation. Some of the PMCs of alternate 



Fig. 1A-1L. Meiotic stages in Brassica campestris L. 1A normal diakinesis (10 bivalents), 1B 2(II), 2(III), 1(IV), 1(VI-8-shaped alternate R), 1C 7(II), 1(VI-C zig-zag), 1D 3(II), 1(VIII-C), 1(VI-R), 1E 4(II), 1(IV-C), 1(VIII), 1F 3(II), 1(IV-C), I(X-R attached to nucleolus), 1G 1(IV-C), 1(VIII-C) arrow, 1(VIII), 1H-2(I), 7(II), 1(IV-8 shaped R), one bivalent showing late disjunction of chromatin material (arrow head), 1I random translocation ring, 1J 3(II), MA, 1K 3(II), 1(IV), 1(X), 1L 3(II), 2(IV-R-alternate), 1(VI).(R-ring, C-chain, MA-multivalent association, $40 \times$, scale bar $=4.2 \mu \mathrm{m})$

configuration showed 8 -shaped quadrivalent and hexavelent orientations, forming $2+2$ bi-rings and $3+3$ bi-rings, respectively, as shown in Figs. $1 \mathrm{~B}$ and $1 \mathrm{H}$. Adjacent orientation has been noticed in the case of a ring forming a simple loop, while some PMCs had shown the prevalence of zigzag hexavalent chain configurations (Fig. 1C). A lack of chiasmata could be the reason for chains that also have a pronounced number of PMCs (Figs. 1D, 1E, 1G). On the whole, the frequency of multivalent association harmonized with the increase in the dose of mutagens. The percentage of quadrivalents was more pronounced and was observed to occur at all mutagen doses, although the percentage of dodecavalents was counted the least, only appearing at $60 \mathrm{Kr}+0.3 \%$ dose of combined 
Table 1. Multivalent associations and pollen fertility as a consequence of reciprocal translocation in response to varying dose of combined treatment

\begin{tabular}{|c|c|c|c|c|c|c|c|c|c|c|c|}
\hline \multirow{2}{*}{$\begin{array}{l}\text { Conc. } \\
\mathrm{Kr}+\%\end{array}$} & \multirow{2}{*}{$\begin{array}{c}\text { Total } \\
\text { PMCs } \\
\text { scored }\end{array}$} & \multicolumn{8}{|c|}{ Chromosome association (\%) } & \multirow{2}{*}{$\begin{array}{l}\text { TMA } \\
(\%)\end{array}$} & \multirow{2}{*}{$\begin{array}{l}\text { Pollen fertility } \\
(\%)\end{array}$} \\
\hline & & I & II & III & IV & VI & VIII & $\mathrm{X}$ & XII & & \\
\hline Control & 300 & $0.566 \pm 0.01$ & $18.562 \pm 0.03$ & - & - & - & - & - & - & 0 & $99.988+0.01 *$ \\
\hline $15+0.3$ & 246 & $1.106 \pm 0.04$ & $17.940 \pm 0.72$ & - & $0.508 \pm 0.05$ & - & - & - & - & 0.508 & $88.294 \pm 0.05$ \\
\hline $30+0.3$ & 290 & $1.350 \pm 0.02$ & $15.260 \pm 0.09$ & - & $0.888 \pm 0.035$ & $0.486 \pm 0.005$ & $0.814 \pm 0.01$ & $0.325 \pm 0.002$ & - & 2.513 & $60.604 \pm 0.17$ \\
\hline $45+0.3$ & 263 & $1.532 \pm 0.01$ & $14.454 \pm 0.10$ & $0.364 \pm 0.02$ & $1.300 \pm 0.016$ & $1.096 \pm 0.017$ & $0.934 \pm 0.002$ & $0.456 \pm 0.008$ & - & 4.150 & $51.846 \pm 0.42$ \\
\hline $60+0.3$ & 315 & $1.696 \pm 0.013$ & $12.188 \pm 0.03$ & $0.694 \pm 0.01$ & $1.550 \pm 0.015$ & $1.256 \pm 0.017$ & $1.000 \pm 0.02$ & $0.612 \pm 0.011$ & $0.166 \pm 0.03$ & 5.278 & $45.874 \pm 0.76$ \\
\hline
\end{tabular}

*Values are Mean \pm SE

Legend: PMC, pollen mother cells; TMA, total frequency of multivalent association

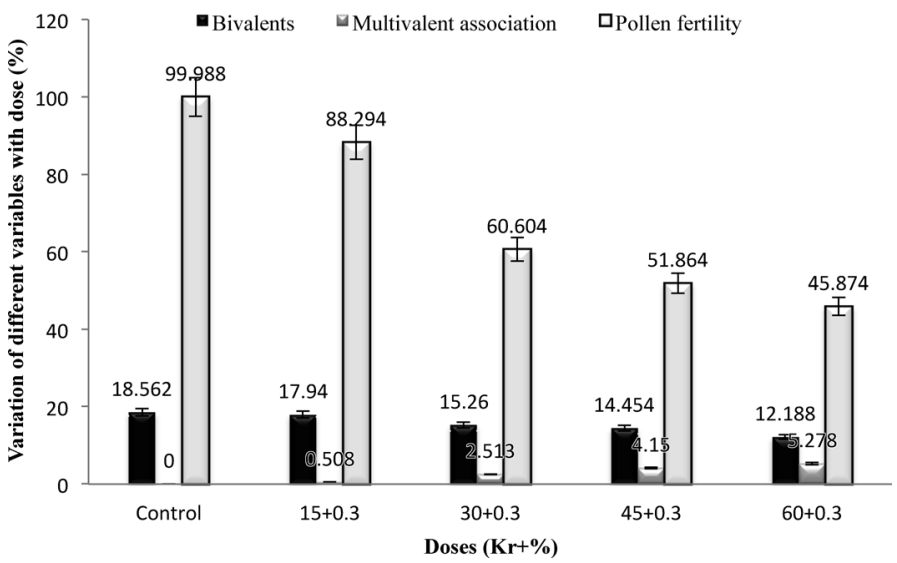

Fig. 2. Frequency of bivalents, multivalent association and pollen fertility along with increasing dose.

treatment. At this particular dose, the greatest spectrum of associations was documented to present trivalents $(0.694 \%)$, quadrivalents $(1.55 \%)$, hexavalents $(1.256 \%)$, octavalents $(1.00 \%)$, decavalents $(0.612 \%)$ and dodecavalents $(0.166 \%)$, in other words the dose proved to be highly hazardous (Table, Fig. 1). However, the lowest dose was not as detrimental as that of the aforementioned, having only a $0.508 \%$ quadrivalent association. Besides these associations, several meiotic irregularities, such as unequal separation, problems in spindle fibres, asynchronous chromosomes, and laggards during meiotic course, have been discernible. Despite this, a large proportion of PMCs behaved normally, showing the presence of 10 bivalents. Moreover, the trend of pollen fertility associated reciprocally with the frequency of multivalent association and doses; ranging from $88.294 \%$ to just $45.874 \%$ at $15 \mathrm{Kr}+0.3 \%$ to $60 \mathrm{Kr}+0.3 \%$ doses, respectively. On the other hand, fertility was directly proportional to the decreasing tendency of bivalent formation (Table 1, Fig. 2). More interestingly, in some meiocytes, the early/late disjunction of bivalents has also been registered (Fig. $1 \mathrm{H}$ ), which could be the reason for the occurrence of univalents and the tendency for increase in parallel with the increasing doses (Table 1). This is because the formation of univalents is also a complex process, involving misdivision during meiosis, when centromeric chromosomes erroneously inserted in traction fibres lead to a-misdivision (obligatory), or the lack of such an insertion, which causes p-misdivision (facultative), as proposed by Sanchez-Monge (1950). Thus, it is reasonable to surmise that a decreasing tendency of bivalents and a parallel increasing frequency of multivalent association and univalents might be the probable cause for such meiotic manifestations, encompassing RT and other meiotic irregularities, resulting in decreased pollen viability in the test crop, that in turn severely affected the fertility of the present crop. 


\section{Discussion}

The results clearly revealed the cytogenetic authentication of the fascinating event of RT during microsporogenesis in Brassica campestris L., which was identified morphologically as reduced fertility of plants prior to cytological analysis. During observation, it was found that few plants bear flowers but later, in place of pods, the rudiments of petals were observed on the axis. These plants, which were suspected and cytologically tested, showed preponderance of chromosomal association and reduced pollen fertility that might perhaps be attributed to the presence of reciprocal translocation. The induction of multivalent association via single treatments has been known in many plant species, e.g. Pennisetum typhoides (Pantulu 1967), Vicia faba (Sjodin 1971), Vinca rosea (Sudhakaran 1971), Oryza sativa (Reddi and Reddi 1975), Phlox drummondii (Verma and Raina 1982), watermelon (Zhang et al. 2012). Dispite this, induced RT by combined treatment hardly ever occurs. The application of gamma rays might be the probable cause of physiological imbalance in the cells, producing some chemical substances that disrupt the synthesis of DNA in the cells following breakage and restitution of the broken segments, thus resulting in chromosome associations (Basi et al. 2006). The exact role of EMS in inducing chromosome association in the present case is not clear. However, in our opinion, it is possible that it was the fact that gamma rays broke the chromosomal segments in the cells while the rejoining was under EMS control that might have induced mutation at gene level, so that a specific or hindered gene started to express itself and was accountable for the unusual pairing of arms of non-homologous chromosomes. More precise efficacy of EMS for point mutation has also been stated by Bentley et al. (2000), who reported on a series of 16 EMS-induced mutations in the awd gene in Drosophila, while Greene et al. (2003) reported on 192 genes, with an average of 10 mutations per gene, in Arabidopsis; these reports, concur with our inference of induced mutation. Further, Kaul (1977) was of the opinion that the breakage and exchange of heterologous chromosomes is genetically conditioned and controlled, thereby eliminating the 'chance factor' operating for the predominance of either ring or chain or both. If the interchanged segments of heterologous chromosomes are long, it is possible that they are going to form rings. If chiasmata are not formed in all the arms, chains instead of rings are formed (Burnham 1956). Ghosh and Datta (2006) reported that predominant occurrence of adjacent orientation in quadrivalents in heterozygotes is expected to induce a high frequency of non-viable male gametes following the duplication and deficiency of genes. In the present study, alternate orientation was frequently found, rather than adjacent, and both produced male sterility; this appears to follow the duplication and deficiency of genes mentioned by Ghosh and Datta (2006).

Due to translocation, independently assorting genes may develop linkage relationships and develop the tendency to inherit together from generation to generation. Thereby, they reduce the possibility of variations, hence seldom participate, or indeed may create a gap in the process of organic variation. Emerson (1931) studied linkage within a translocation complex in Oenothera. Some degree of infertility is an inevitable consequence of interchanges (Burnham 1962, Garber 1972). Hence, they have the capability to produce aborted pollen grains leading to semi-sterility in plants. Considering other abnormalities, bridges might be formed due to the failure of the rejoining of broken segments of chromosomes, while the appearance of unorientation may have been due to spindle malfunctioning. Thus, the above mentioned meiotic manifestations account for the lower pollen viability of the test crop.

On the whole, the conclusion which can be drawn from the above observations is that reciprocal translocation and other meiotic manifestations were the main reasons for the prevalence of sterility in some plants raised from combined treatment. Therefore, these were the reasons for the drastic abortion of male gametes in the treated plants. In subsequent generations, it will be established whether this sterility passes to the next generation or not; as mentioned earlier, the double interchange complex has the tendency to be inherit together for several generations when developing 
linkages.

\section{Acknowledgements}

We are grateful to NBPGR, New Delhi, for providing inbred seeds of Brassica campestris L. accession number-IC363713 and NBRI, Lucknow, for providing the irradiation facility. Thanks are also due to the members of the Plant Genetics Laboratory for their support and suggestions. One of the authors (Kshama Dwivedi) is extremely grateful to the Department of Science and Technology (DST), New Delhi for providing financial assistance as an Inspire Fellowship.

\section{References}

Basi, S., Subedi, L. P., KC, G. B., and Adhikari, N. R. 2006. Cytogenetic effects of gamma rays on indica rice radha-4. J Inst Agric Anim Sci. 27: 25-36.

Belling, J. 1914. The mode of inheritance of semisterility in the offspring of certain hybrid plants. Z Indukt. Abstamm. Vererbungsl. 12: 303-342.

Bentley, A., MacLennan, B., Calvo, J., and Dearolf, C.R. 2000. Targeted recovery of mutations in Drosophila. Genetics 156: $1169-1173$.

Burnham, C. R. 1956. Chromosomal interchanges in plants. Bot. Rev. 22: 419-522.

Burnham, C. R. 1962. Discussions in Cytogenetics. MN, Burgess.

Emerson, S. H. 1931. The inheritance of certain characters in Oenothera hybrids by different chromosome configurations. Genetics 16: $325-348$.

Evans, D. A., and Reed, S. M. 1981. Cytogenetic techniques. In: Thorpe, T. A. (ed.) Plant Tissue Culture: Methods and Application in Agriculture. Academic Press Inc., New York.

Garber, E. D. 1972. Cytogenetics: an introduction. McGraw Hill Inc., New York.

Generoso, W. M., Russell, W. L., Huff, S. W., Stout, S. K., and Gosslee, D. G. 1974. Effects of dose on the induction of dominant-lethal mutations and heritable translocations with ethyl methane sulfonate in male mice. Genetics 77 : $741-752$.

Ghosh, A., and Datta, A. K. 2006. Gamma-rays induced reciprocal translocation in Nigella damascene L. (Love-in-a-mist). Caryologia 59(1): 31-36.

Greene, E. A., Codomo, C. A., Taylor, N. E., Henikoff, J. G., Till, B. J., Reynolds, S. H., Enns, L. C., Burtner, Johnson, J. E., Odden, A. R., Comai, L., and Henikoff, S. 2003. Spectrum of Chemically Induced Mutations from a LargeScale Reverse-Genetic Screen in Arabidopsis. Genetics 164: 731-740.

Gupta, R. C., Himshikha Rana, P. K., Kumar, P., and Singhal, V. K. 2010. First report of structural heterozygosity in Artemisia parviflora (Asteraceae) from Parvati Valley in Kullu District (Himachal Pradesh, India). Bot Serb 34(1): 63-66.

Hsieh, S. C. 1961. Analysis of reciprocal translocation in rice-mutation in rice by X-rays. Bot. Bull. of Acad. Sinica (Taiwan) 2: 111-117.

Kalyani, S., Jain, S. K., Saxena, R. K., Chowdhary, N. K., and Uprety, M. 1995. Effect of storage temperatures and seed moisture contents on viability of Brassica juncea seeds. Indian Journal of Plant Genetic Resources 8(1): 89-94.

Kaul, M. L. H. 1977. Cytogenetics of white Allium I. Translocation heterozygosity. Cytologia 42: 681-689.

Kumar, G., and Singh, V. 2003. Meiotic behaviour of induced translocation heterozygote in pearl millet (Pennisetum typhoides). Cytologia 68: 245-248.

Mahama, A. A., Deaderick, L. M., Sadanaga, K., Newhouse, K. E., and Palmer, R. G. 1998. Cytogenetic analysis of translocations in soybean. Caryologia 51(2): 149-158.

Muller, J. H. 1930. Oenothera like linkage of chromosomes in Drosophila. J. Genet. 22: 335-357.

Pantulu, J. V. 1967. Chromosomal alterations in pearl millet induced by gamma rays. Nature 213: 101-102.

Reddi, V. R., and Reddi, T. V. V. S. 1975. A case of induced double interchange lice involving six chromosomes. Mut. Res. 33: 421-424.

Sanchez-Monge, E. 1950. Univalent mechanism and misdivision. An. Estac. Exp. Aula Dei. 2: 1-11.

Sareen, P. S., Mangotra, R., and Koul, A. K. 1998. Genetic diversity among Plantagos. XXXIII. Interchanges in Plantago ovata Forsk. Caryologia 51(2): 149-158.

Sharma, G., and Gohil, R. N. 2011. Occurrence of differential meiotic associations and additional chromosomes in the embryo-sac mother cells of Allium roylei Stearn. J. Genet. 90: 45-49.

Shukla Nee Tripathi, R., and Kumar, G. 2009. Meiotic analysis of induced translocation heterozygotes in Lathyrus sativus L. Cytologia 74: 89-93. 
Sjodin, J. 1971. Induced translocations in Vicia faba L. Hereditas 68: 1-34.

Sudhakaran, I. V. 1971. Meiotic abnormalities induced by gamma rays in Vinca rosea Linn. Cytologia 36: 67-79.

Verma, R. C., and Raina, S. N. 1982. NMU induced translocation and inversion in Phlox drummondii. Cytologia 47: 609614.

Zhang, Y., Cheng Z., Maa J., Xian F., and Zhang X. 2012. Characteristics of a novel male-female sterile watermelon (Citrullus lanatus) mutant. Sci. Hortic. 140: 107-114. 